\title{
THE ROLE OF THE SICKNESS FUNDS IN THE BELGIAN HEALTH CARE MARKET
}

\author{
WALTER NONNEMAN ${ }^{1}$ and EDdy VAN DOORSLAER ${ }^{2}$ \\ 'Department of Economics, University of Antwerp (UFSIA), Prinsstraat 13 B-2000 Antwerp, \\ The Netherlands and 'Department of Health Policy and Management, Erasmus University, \\ P.O. Box 1738, 3000 DR Rotterdam, The Netherlands
}

\begin{abstract}
This article reviews some of the salient features of the Belgian health care finance and delivery system. Special attention is paid to the role played by the third-party payers, i.e. the Health Insurance Associations (HIAs) in administering the compulsory national health insurance program. It is shown how, despite extensive government regulation, the markets for GP, specialist and hospital services exhibit fierce competition of the non-price variety.

Next, the paper considers the three problems perceived to be the most pressing ones at present: (i) the problem of raising sufficient revenues to cover the public share of health expenditures; (ii) the (related) cost containment problem; and (iii) the problem of ensuring efficiency through appropriate incentive mechanisms.

Finally, two recently proposed options for reform are discussed and complemented with a third proposal based on the ideas of regulated competition. It is concluded that strengthening the role of the third-party payers remains crucial in any attempt to reshape the system to make it efficient and affordable while keeping it equitable.
\end{abstract}

Key words -managed competition, Belgium, health care market, reform, financial accountability

\section{INTRODUCTION}

At first glance, health care in the nineties does not seem to be a major social policy problem in Belgium. In comparison to as neighbour countries, Belgium seems to be achieving a similar performance in terms of health outcomes while spending a slightly lower share of its GDP [1]. Most of the essential characteristics of the present day Belgian health care financing system were decided upon in the aftermath of the Second World War. This paper reviews some of these features and asks whether they are still appropriate in view of the recent financing problems. The next section gives a description of the main characteristics of Belgian health care financing and delivery and evaluates the respective roles of markets and regulation in achieving allocations of resources. Section 3 gives an account of the economic problems perceived to be currently the most prominent. In section 4 some possible developments in the near future are considered. After a discussion of two recently proposed opposite scenarios for reform, the potential for a more drastic reform is discussed which includes elements of what might be called a Belgian version of managed competition.

\section{HEALTH INSURANCE AND HEALTH CARE IN BELGIUM}

Belgium has a compulsory national health insurance, covering major health risks of the entire population and major and minor risks for about $88 \%$ (in 1991) of the population. Compulsory health insurance is combined with a private system of delivery of health care, based on independent medical practice, free choice of doctor and-until recently-predominantly fee-for-service payment. Although health insurance is compulsory, management and administration of insurance is predominantly left to nongovernmental non-profit organizations (i.e. the mutual aid funds or 'mutualiteiten'). The role of government is limited to regulation and partial funding, leaving providers with a large degree of sovereignty in both clinical and managerial matters.

\subsection{Health insurance associations (HIAs)}

The national health insurance programs are administered by six Health Insurance Associations (HIAs) which are the main third-party purchasers of health carc in Belgium. These national associations group a much larger number of local mutual aid funds. Although there are six associations, two dominate the scene i.e. the National Alliance of Christian Mutual Funds (covering about $45 \%$ of the population) and the National Union of Socialist Mutual Funds (covering about $29 \%$ of the population). The main features of these HIAs are their non-profit status, their ideological alignment and their decentralized administration.

HIAs are basically non-profit, non-commercial organizations. By law they are entrusted with a primary role in health insurance and given a (joint) 
monopoly position in the compulsory health insurance market. Furthermore, mutualities are incorporated organizations but exempted from taxes and other rules governing commercial ventures. Historical circumstances explain the present-day ideological alignment of HIAs. Early mutual aid societies gained financial stability, political protection and subsidies by associating with the labour movement. As labour unions were organized along different ideological positions-catholic, socialist and liberal-the mutual aid societies aligned accordingly. At present, this ideological alignment is still very important. Each of the major HIAs has its supporters in its respective political party and labour movement. Consequently, competition between HIAs often has political and ideological overtones. Early day local mutual aid societies searched greater financial stability by forming larger risk pools. Local mutual aid societies of the same ideological family grouped together and formed regional federations. Later, regional federations grouped together and formed national alliances. This tree-layer decentralized structure still exists today, although the influence of local alliances is rather limited.

HIAs have essentially a captive and non-contestable market in the health insurance business. They gained this position in the aftermath of the Second World War. Before World War II health insurance was not compulsory and HIAs collected fees from members. HIAs were however subsidized, encouraging growth in membership of HIAs so that almost three quarters of the population was protected to some extent $\because$ a local mutuality. After the World War II, the collection of health insurance contributions was centralized and embedded in a global system of social security. Most importantly, HIAs obtained exclusive access to a captive market when legislation was enacted that made membership of a mutuality compulsory for all wage earners or salaried persons and their dependents. Later, this captive market was extended further as enrolment in a mutuality was made compulsory for self-employed and their dependents (in 1963) and government employees (1965). Recent legislation on the legal status of HIAs (1990) confirmed their non-contestable position as administrators of national health insurance.

\subsection{National health insurance programs}

The national health insurance program consists of a so-called 'general regime', covering major as well as minor health risks for 8.6 million private and public sector wage-earners and salaried personnel and their dependents, and a 'regime for the self-employed', covering only major health risks for 1.2 million self-employed and their dependents. Each program covers the reimbursement of medical care costs, but also covers income compensation.

Contributions for all social security programs are collected by a government agency. They consist of a flat tax on labour earnings paid by employers, employed and self-employed. This is supplemented by a government subsidy replacing the contributions of the beneficiaries of certain social security programs (unemployed, aged, poor, ...). Earmarked contributions for health insurance are transferred to the Institute for Sickness and Invalidity Insurance (INAMI/RIZIV). This is the specific government agency responsible for health and disability insurance which distributes the funds over the six HIAs, supervises HIAs, negotiates fee schedules with physicians and other practitioners and coordinates policy in general. Funds are distributed over the HIAs according to their membership contributions. Government subsidies are distributed using a specific formula, taking into account the composition of beneficiaries of each HIA of other social security programs.

It can be seen from Table 1 [2] that as a result of this financing mechanism the largest HIA (the Christian) received a larger share of the total membership contributions (i.e. $48.3 \%$ ) than its share of total membership (i.e. $44.7 \%$ ) but a smaller share of total government subsidies (i.e. $36.6 \%$ ). The opposite is true for the second largest HIA (the Socialist) whose contributions share was lower and whose subsidy share was larger than its membership share. For most other HIAs, the respective shares of contributions and subsidies are more in line with their membership shares.

Any remaining discrepancies between total expenditures and total revenues of an HIA are covered through a system of preliminary financing. De facto, HIAs with a surplus end up prefinancing HIAs with a deficit, so that eventually expenditures and revenues are equalized for each HIA. Until 1980 HIAs received $6.5 \%$ of total turnover as administration costs. These costs are now budgeted and only adjusted for consumer price inflation.

Medical care benefits are limited to major risks for the self-employed, whereas for wage and salary earners coverage is very broad. All physicians-GPs,

Table 1. Percentage distributions of membership, sources of revenue and expenditures by HIA in 1990

\begin{tabular}{lccccc}
\hline HIA & Membership & Contributions & Government subsidy & Total revenue & Expenditures \\
\hline Christian & 44.73 & 48.26 & 36.62 & 42.68 & 41.65 \\
Socialist & 28.89 & 25.29 & 35.02 & 29.63 & 31.61 \\
Occupation & 14.99 & 15.43 & 15.20 & 15.33 & 14.88 \\
Liberal & 6.36 & 6.27 & 7.45 & 6.80 & 6.67 \\
Neutral & 4.25 & 4.15 & 4.85 & 4.64 & 4.45 \\
Auxiliary & 0.78 & 0.60 & 0.86 & 0.92 & 0.73 \\
Total & 100.0 & 100.0 & 100.0 & 100.0 & 100.0 \\
\hline
\end{tabular}

Source: Ref. [2]. 
dentists and specialists - charge fee-for-service and patients have to seek reimbursement from their mutuality. A fee schedule-the so-called 'nomenclature'is established nationally by the INAMI/RIZIV after negotiations between the doctors' syndicates and the HIAs. As a rule, reimbursement is between 60 and $75 \%$ of the negotiated fee. For the poor, the elderly and certain other groups, reimbursement is more generous and up to 90 to $100 \%$.

Hospitalization is covered extensively by national health insurance programs. There is no distinction in coverage between private and public hospitals. Costs of hospital stay and nursing care (hotel costs) are strictly separated from costs of medical services (including laboratory and radiology services). Hospital services are paid for under the negotiated fee schedule for physician services. Patients only pay the coinsurance premiums, as all medical bills are centralized and directly sent to the regional federations of mutualities.

Hospital stay and nursing care is directly funded and regulated by the government through the Ministry of Public Health. Hospitals are budgeted on a cost-per-day basis. Annually a standard cost per day for each hospital, including patient care, nursing, maintenance, depreciation and financial cost, is estimated by the Department of Public Health. This standard cost is based on a mixture of parameters such as historical cost, average cost of a sample of hospitals with similar characteristics, case mix and work load. This standard cost is also the price per patient day for treatment in a general ward. Patients pay a flat price pc- day as a coinsurance contribution and hospitals are reimbursed $75 \%$ of the standard price by the HIAs and the remaining $25 \%$ consists of a subsidy by the Department of Public Health.

The Department of Public Health also sets a target number of patient days, for which the per diem standard cost applies. If more patient days are produced than the target number, then only $30 \%$ of the per diem is received for surplus production. When fewer patient days are logged than the target number, then for the shortfall only $50 \%$ of the per diem is received. These regulations-i.e. determining a standard cost, based on a comparison with structurally similar hospitals and fixing a quotum for the number of patient days - date from 1982. During the eighties and especially in 1990-1991, the system was further refined and transformed into a form of prospective budgeting.

\subsection{Health care delivery}

In Belgium health care delivery is mainly private and based on independent medical practice or 'médecine libérale' [3]. Ambulatory care is dominated by single-handed practices of self-employed physicians, dentists and pharmacists. The country has one of the highest physician per population ratios of the industrialized world viz. 31.7 doctors per $10000 \mathrm{popu}-$ lation in 1990 [4]. Specialists have more control of access to their profession than general practitioners as their number is determined by the availability of training posts in teaching hospitals. In the market for GPs, there are clear signs of excess supply. Newcomers earn incomes so low that the rate-on-return on their education is very low. Even negative rates-onreturn have been calculated for GPs when compared to a banking career in the early eighties in Belgium [5]. Newcomers are no longer capable to sustain a solo practice, and look for salaried employment in the private sector or take up another profession. For specialists there are no real shortages and even surpluses exist in some areas. Specialists usually also have hospital privileges.

An important feature of the delivery system is that patients have a free choice of doctor. This is a powerful competitive stimulus, as some patients switch doctors and shop around, even for the same medical problem. Excess supply, especially in the market for GP services, and free choice of doctor, lead to fierce non-price competition among physicians (mostly through product differentiation). Price cutting and some forms of non-price competition such as advertizing are considered 'unethical' behaviour and are subject to severe penalties administered by the Order of Physicians. Most specialists have an office practice and often work in hospital out-patient departments. Patients do not need a referral from a GP to consult a specialist.

Competition between hospitals for patients, specialists and rights to facilities is fierce, especially since the country is fairly densely covered with hospitals. In 1981 the number of hospital beds per 1000 population was 9.4. This has decreased to 7.9 hospital beds per 1000 population in 1990 , mainly as a result of the conversion of hospital into nursing home beds [4].

About $60 \%$ of all hospitals are non-profit private institutions. A small number of private hospitals is owned by specialists and some $5 \%$ belong to HIAs. The remainder are public hospitals. Apart from a more generous regime of capital funding, there is no difference in the method of financing private and public hospitals. Hospitals draw on two major sources to finance their activities. First, on the prospective budget, based on the standard per diem and the quotum of patient days. Three payers contribute to the total per diem price: patients pay a fixed copayment per day, HIAs pay $75 \%$ of the per diem and the Department of Public Health pays $25 \%$ of the per diem. A second possible source of revenue for hospitals are fee-splitting arrangements with staff physicians.

\subsection{Competition, markets and regulation}

Health insurance and health care in Belgium is, as elsewhere, subject to extensive regulation. A distinct feature of the Belgian system is, however, that it combines compulsory, comprehensive and universal national health insurance with a reliance on patient 
choice, non-government agencies, private (nonprofit) institutions and entrepreneurial medical professionals in delivering health insurance and medical care. In almost every submarket of the insurance and health system, barriers to entry are stiff or prohibitive for newcomers, but within each market there is often a substantial degree of competition, mostly of the non-price variety.

The market for compulsory health insurance is a closed market and non-contestable, leaving no room for new entrants. Existing HIAs as a group have a 'monopoly' position, as they have exclusive rights to funding out of collectively raised social security contributions and government subsidies. As legislation on the recognition of HIAs provides explicitly for the non-profit status of these organizations granting them tax-exemption and other privileges, private for-profit insurance companies are excluded from the compulsory health insurance market. This is in contrast with other compulsory insurance schemes in Belgium, such as for occupational hazards [6], where the government relies entirely on for-profit firms for delivery and administration. Even the residual market for complementary health insurance-i.e. the health risks not covered by the compulsory schemecannot effectively be contested by private for-profit firms. HIAs, by their non-profit tax-exempted position, can provide additional coverage for members at 'non-commercial' rates i.e. rates that would allow for taxes and profits. In addition to this privileged tax position, economies of scale and scope give existing HIAs a 'first-mover advantage', which is difficult to offset even $f_{t}$ - the most efficient and large scale private operator.

Within this captive market of compulsory and complementary health insurance, non-price competition for members between HIAs is fierce. All major HIAs have offices in each municipality or town and members have the option of changing to another mutuality every three months. Although most members are very 'brand-loyal', there is shifting at the margin and competition for new members. Some of the incentives for competition among HIAs are financially driven, but the strive for ideological dominance, political power and influence, and sheer engagement should not be underrated. The main instruments of competition are the 'quality' of service and product differentiation. Most HIAs offer not only additional insurance but other health and welfare related services such as homecare and homemaking, savings accounts for youngsters, holidays for youngsters, etc.

Entry to health care provision markets is somewhat less restrictive and internally highly competitive. Entry to the market for GP services is fairly open. Physicians as a profession over the years lost control over the supply of new GPs as they were unable to restrict the entry of students to medical schools. Student numbers increased rapidly as a consequence both of the drastic extension of health insurance in the sixties, leading to soaring physician incomes, and the almost simultaneous reduction in the real cost of education, through regional decentralization of medical schools [7]. Consequently, there is now a glut of GPs (14.6 per 10000 population or only about 700 patients per GP in 1990), creating room for fierce competition, mostly of a non-price variety. For instance, in comparison to other countries, Belgian GPs have a much larger share of their services delivered at the home of the patient. Regional data show that home calls as a share of total patient contacts clearly correlate with physician density, as more rivals force GPs to substitute patients' time for their own time, thereby lowering patient costs of utilization.

Specialists were more successful in retaining control over access to their profession. Specialist trainees work under supervision of a specialist who pays his trainees out of fees from services delivered to patients. Consequently, new entries depend upon the number of clinical training posts in teaching hospitals, the volume of which is largely controlled by established specialists. Although access to the specialist profession is more restricted, due to the decreasing number of hospital beds in the 80 s there are no real shortages of specialists and even surpluses exist in some specialties.

Competition among physicians is mostly of the non-price variety due to the fact that prices are, to a certain extent, rigid and formed at the national level. General practitioners, specialists and dentists charge fee for service. Prices though are not freely formed in a competitive market but are the negotiated outcome in a market resembling bilateral monopoly. A very detailed and sophisticated fee schedule, the so called 'nomenclatuur', is established nationally by the government agency (INAMI/RIZIV) after negotiations between the physicians' syndicates and the HIAs. Reimbursement is on average $60-75 \%$ of the listed fee and $90-100 \%$ for the poor and the elderly. Each year, a general increase and/or adjustments of fees are negotiated between the HIAs and representatives of physician organizations within government-set budgetary limits. In case of non-agreement, the government is the decision maker of last resort. Physician members are consulted on the outcome of these negotiations and if a qualified majority of all physicians agrees to the new fee schedule, it becomes legally binding for all who have not explicitly objected. In December 1992, for the first time in many years, negotiations lead to a stalemate. The government decided unilaterally on an across-the-board increase in fees, lower than physician representatives proposed, and put its proposal to the vote. The majority of physicians rejected the proposed fee increase, so that, in 1993 individual physicians could in principle determine prices freely. However, despite this dispute no important fee changes above the governments' proposal, have been reported, indicating a general reluctance on the part of physicians to compete with prices, which is no surprise in view of the abundant supply of physicians. 
This 'nomenclatuur' plays an important role in the market for physicians' services. In the GP market, as patients have free choice of doctor and do shop around and as a consequence of the ample supply of GPs, competitive market pricing would most certainly mean lower prices. However, the fee schedule sets an effective price floor for GP services or is, at least, a major 'focal point' for pricing GP services. The Order of Physicians, with judicial power similar to a court of law, considers pricing below the negotiated 'unethical practice' and even temporarily suspends unabiding physicians from medical practice. This effective threat limits downward price competition as potential gains in market share and income from charging lower income do not outweight potential losses from being barred from practice.

The 'nomenclatuur' also comprises specialist services. Similar to the market for GP services, for those specialties known to be in excess supply (paediatrics, obstetrics, ...) the schedule acts as an effective price floor. For specialties in excess demand and for the services of renowned specialists, demand is simply rationed by price as there is no legal or 'ethical' impediment to charging fees above the negotiated fee [8]. Extra billing-i.e. charging fees above the standard tariff in the 'nomenclatuur'-is not uncommon for specialist hospital services. Furthermore, income dependent price discrimination is often practiced and extra billing is not always tax reported.

Again, entry in the market for hospital services as a whole is restricted by regulation. One of the conditions for subsidization by the Department of Public Health is that a hospital must obtain a license to operate a certain number of beds in each broad category (acute care, surgery, maternity, etc.). Similarly, operating heavy technology (e.g. NMR) is also subject to licensing as a condition for reimbursement or subsidization. Consequently, the government has an instrument to control global hospital capacity. It has used these powers effectively to reduce the number of beds over the years and to transform the number of (expensive) hospital care beds to (less expensive) nursing home beds.

The independent character of the medical profession in Belgium is characterized by the contractual arrangements in private hospitals between the hospital and its physicians staff. Most specialists are self-employed, earning their income on a fee-forservice basis. In most private hospitals, but also in public hospitals, physicians generally obtain the privilege of access to hospital facilities only in return for an agreement to share fees with the hospital. The precise fee-splitting is subject to negotiation and depends upon relative scarcity or abundance in a speciality, the extent of hospital facilities, hospital reputation, reputation of the specialist, etcetera. In public hospitals, as well as in some private hospitals, physicians often pool their fees. They are then paid a basic salary, augmented with some pre-negotiated share of the pool. These fee-splitting arrangements are part of the competitive instruments which hospitals use in attracting specialists and their patient clientele. On the other hand, revenues from fee-splitting are an increasingly important share of hospital income.

A specific example of the competitive and entrepreneurial nature of Belgian health care delivery, which also clearly illustrates what can go wrong in poorly regulated markets in medical care services, is that of laboratory testing (clinical biology). Up to 1985, all laboratory testing was on a fee for service basis, with no limits or control on the prescription of tests other than self-regulation by the Order of Physicians. Technological advances not only lead to new diagnostic tests but also enabled low cost testing through automation, making testing a highly profitable business. The absence of any copayments by patients and the 'advertising-through-training' directed at physicians lead to fairly 'frivolous' use of tests by GPs as well as specialists. Fee-splitting between laboratories and prescribing physicians or other (illegal) kickbacks rewarding high prescribers were fairly common practice. Also, hospitals used their laboratories (and radiology) to generate additional revenues from diagnostic services to inpatients and outpatients. In many cases, this was a defensive response to compensate for reductions in their other main source of income i.e. the per diem cost reimbursement. Various attempts to control costs of diagnostic testing were implemented. A nationwide data management system was imposed so that high prescribers could be identified and, eventually, called to explain their prescribing behaviour. Since 1985, the Department of Public Health imposed a national budget on the fee for service system, with the threat of reducing fees if the budget was exceeded. Prescribers-each fearing free riding by others at their expense-responded by an explosion in quantity, forcing the Department to reduce the fees by $30 \%$ in 1988 . Since 1989 , the fixed budget is almost strictly enforced by abolishing the fee for service system for hospital patients and replacing it by a daily ratc and a fee per admission. Since October 1992, a new system for out-patient tests was introduced. Basically, fees were reduced drastically, globalized and made degressive. Also individual prescription behaviour is closely monitored and heavy prescribers are asked for an explanation.

The overall consequence of the fact that Belgian health policy has until recently relied almost exclusively on public control of fees but at the same time maintained fee for service payment of essentially private providers, seems to be that Belgium has a 'low prices-high volumes' health system.

\section{CURRENT PROBLEMS}

Before venturing into problems and reform proposals it is important to remind that the Belgian health care system has many strengths. Contrary to 
many other countries, equity and access to care does not seem to be a major issue and expenditures per capita and growth are not excessive compared with neighbour countries.

According to a recent OECD Health Policy Study comparing health systems and reform in seven OECD countries:

The Belgian health care system demonstrates many strengths. It offers comprehensive compulsory health insurance cover to $85 \%$ of the populations and compulsory cover for major risks to the remaining $15 \%$ of the population. This ensures a high level of solidarity and equity in access. Patients enjoy greater freedom of choice of provider than in any of the other six countries in this study. Consumers are free to choose both their insurer and their provider [...] The system also gives providers a great dea of autonomy [...] the system seems to be remarkably responsive to patients. Access to GP services seems to be particularly quick and convenient, and it is said that there are few people waiting for hospital in-patient care. [3, p. 37].

One should take these important and enviable strengths in mind, when discussing the system's problems and especially when making proposals for reform.

\subsection{Financing health care}

Financing health insurance and medical care costs is one of the recurrent policy discussions. Compared with other countries, health care costs in Belgium cannot be considered excessive. According to the OECD statistics, Belgium spent only $7.9 \%$ of its GNP on health care in 1991, which is below the average of neighbouring European countries [9]. However, it bas recently been argued that the OECD figures underesurnate the true expenditures on health. By incorporating also a number of expenditive categories (e.g. by regional authorities) on health care, Wouters et al. [10] have estimated that in 1987 already 7.990 of GDP was spent on health care. This estimate was recently updated to $9.8 \%$ of GDP in 1990 [11].

The relative shares of the various sources of finance for health care have only been calculated for 1987 and 1990. In $198736 \%$ was financed from social security contributions, $39 \%$ from general taxation, $12 \%$ from out-of-pocket payments, $3 \%$ from voluntary insurance and the remaining $10 \%$ represents a social security deficit [12]. Assuming that the deficit will also be covered by an increase in either the tax or the social security share, it implies that about $85 \%$ was financed from public revenues. In $1990,32 \%$ was financed from taxes, $\mathbf{5 4 . 5 \%}$ from social and voluntary insurance premiums, and $13.5 \%$ from direct payments of health care users. This means that, between 1987 and 1990, the share financed from public sources has decreased slightly, mainly as a result of the decrease in the tax-financed share of expenditures.

Social security contributions are a flat-tax on wages, shared by employers and employees (currently at $6.35 \%$ of gross wages with no upper limit). Funding almost half of health insurance by a labour tax has important consequences for the political economy of the sector. In case of funding out of general taxes, the beneficiaries and providers of a service, for whom the stakes are often substantial and clearly visible, often successfully lobby for more expenditures. For the individual tax payer, it is often not worthwhile to put up a countervailing lobby against those special interests as resulting tax increases are too small to justify expenses to put up a defense.

The partial funding of the health insurance program by a flat labour tax changes this standard public choice mechanism. Increased spending, insofar as it is not met by an increase in government subsidies, necessitates higher labour taxes. These tax increases have clear and localized effects. Rising labour costs drive out marginal businesses or induce job losses. The impact of higher social security spending directly affects labour market conditions by inducing either lower net wages or increases in unemployment due to higher labour costs. The dominant HIAs (Christian, Socialist and Liberal) are closely linked to the ideologically aligned trade unions, and are considered part of the same 'social movement'. As decreasing net wages or rising unemployment is not in the trade unions' interest, HIAs may come under pressure from their associated unions to control excessive growth of medical costs and insurance expenditures. In this mixed funding system, HIAs, trade unions and employers' organizations are forced to share part of the responsibility with the government to keep health care costs in check. In this way, the reliance on payroll taxes to finance a large part of the health insurance bill and its repercussions on the labour market may provide a stimulus to HIAs (as part of the same 'social movement' as trade unions) to act as a countervailing power vis-à-vis health care providers.

Recently, the government called upon unions and employees to make a 'new social deal'. Apart from structural measures to curb the dynamics of social security spending, it was suggested that the strong reliance on wage taxes should be reduced and that alternative methods, such as valuc added taxes, taxes on energy or general taxes, should be used to contribute to funding social security. Relying more on non-labour taxes would alter the present public choice mechanism. It might provide less of an incentive for social organizations (HIAs and trade unions) to countervail the power of providers of social security programs and pressures from beneficiaries of social security. More of this countervailing effort would be required from the government. Unfortunately, the Belgian political class is certainly not renowned for fiscal orthodoxy and restrain. Hence, it is possible that a shift in financing social security will lead to expenditure increases, more direct government control and eventually more fiscal problems.

Although financing health insurance is a recurrent policy issue, and a pressing one in view of the present depressed economic climate, one should not drama- 
Table 2. Annual growth rates of health care revenues and expenditures, 1971-1989

\begin{tabular}{lccccc}
\hline & \multicolumn{2}{c}{$1971-1989$} & & \multicolumn{2}{c}{$1979-1989$} \\
\cline { 2 - 3 } & Average & SD & & Average & SD \\
\hline Revenues & 12.13 & 9.76 & & 6.58 & 6.20 \\
$\quad$ Government & 11.29 & 6.05 & & 7.74 & 2.64 \\
$\quad$ Non-government & 11.59 & 7.19 & & 7.17 & 3.01 \\
$\quad$ Total & 11.31 & 6.85 & & 6.53 & 2.72 \\
Expenditures & 2.52 & 2.12 & & 1.96 & 1.61 \\
GNP (real) & 6.06 & 2.82 & & 4.53 & 1.58 \\
Deflator (GNP) & & & & &
\end{tabular}

Source: Ref. [27].

tize this problem. Growth in Belgian health expenditures has, by international standards, not been excessive over the last twenty years and real growth is reasonably well under control (see Table 2). As revenues from payroll contributions are cyclical and closely linked to the level of economic activity, this variability often leads to short-term problems of financing health expenditures. However, despite its dependence on economic activity, growth in revenues from contributions is relatively more stable than revenues from government sources.

In Table 2 it is shown that the standard deviation of the average annual growth rate is much higher for the revenues from government sources (i.e. from general taxes) than from non-government sources. In the period 1979-89, nominal growth rates have gone down and become more stable, and this was especially the case for the non-government revenues. It therefore seems that at least part of the recurrent financial strain on the system is in the whimsical nature of governt: 'nts, rather than in the business cycle. Consequently, more reliance on funding out of general taxation rather than on payroll contributions is likely to make revenues less stable as they will be more dependent upon the good fortune of political coalitions and the changing mood of the bodies governing the country.

\subsection{Controlling costs}

The health care cost containment debate is closely related to the financing problems. In 1989 a 'Round Table Conference', organized by the Department of Social Affairs, concluded that mixed contributory and tax financing has to be maintained as the basis for funding, but also that social security contributions (now up to $40 \%$ of total wage costs) should not increase and that the share of health insurance in social security could not rise at the expense of other benefits. Furthermore it was concluded that the bulk of health expenditure should be covered by general taxation. However, in view of the country's structural fiscal mess, with a public debt far exceeding GNP, it is unlikely that funding out of gencral taxes can be increased substantially.

Another option is to increase cost-sharing by patients. The present government recently decided to increase cost-sharing, thereby shifting health care costs of about 7.5 billion BF (some $2 \%$ of total reimbursements) to the patients. It is realised, however, that its revenue generating capacity is fairly limitcd and policy makers are fearful of the equity problems arising from an extensive use of cost-shifting to patients and consumers. Income-related maximum annual copayment amounts were introduced to mitigate the adverse effects of this increased costsharing for low-income families.

As the immediate prospects for increases in revenues are dim, control of expenditure has been the main goal of regulatory efforts. Recent governments have opted for more direct government regulation, rather than providing regulatory incentives and instruments for self-regulation. In 1990, legislation was adopted allowing the government (the Department of Social Affairs) to fix a global budget for health care expenditure and a division of it over several subsectors. To ensure that budgetary targets are met, a budget control commission is set up, obligatory correction mechanisms - such as automatic downward fee adjustment if budgets are overrun, obligatory refunding by high-cost providers, etc.-are provided for, as well as extensive powers for the Minister of Social Affairs to intervene directly when HIAs and providers do not meet budgetary targets. The evidence on the success of this approach is rather mixed as can be seen from Table 3 .

As in most other countries, both nominal and real expenditure growth was lower in the seventies than in the eighties. Tighter budgetary control mechanisms were implemented in 1991. The substantial increases in real growth in 1990/1992 is attributable to exceptionally high increases in wages and salaries of health workers, rather than to increased volumes in health services. A substantial part of the high 'real' growth rates between 1989 and 1991 is therefore explained by the fact that the nominal growth was deflated using the general consumer price index rather than a health care specific price deflator. The negative real growth in the first semester of 1992/1993 could be a first consequence of the closer budget monitoring system.

\subsection{Efficiency}

According to the OECD survey study, the Belgian health care system has some desirable features with respect to ensuring efficiency viz.:

[. . . ] it seems likely that Belgium can continue to rely on its

Table 3. Growth in health care expenditures in Belgium, 1969-1993

\begin{tabular}{lccc}
\hline Period & $\begin{array}{c}\text { Nominal } \\
\text { growth }\end{array}$ & $\begin{array}{c}\text { Consumer price } \\
\text { index }\end{array}$ & $\begin{array}{c}\text { Real } \\
\text { growth }\end{array}$ \\
\hline $1969-1974$ & 15.44 & 6.41 & 9.03 \\
$1974-1979$ & 13.54 & 7.28 & 6.26 \\
$1979-1984$ & 8.28 & 7.14 & 1.14 \\
$1984-1989$ & 6.49 & 2.36 & 4.13 \\
$1989-1990$ & 8.76 & 3.45 & 5.31 \\
$1990-1991$ & 11.95 & 3.25 & 8.70 \\
$1991-1992$ & 10.30 & 2.43 & 7.87 \\
$1992-1993$ (1st sem) & 2.17 & 2.50 & -0.34 \\
\hline
\end{tabular}

Source: Ref. [9]. 
strong traditions of consumer choice and autonomy of provider to ensure competition among providers, a high level of responsiveness to demands and a high level of patient satisfaction. [3, p. 42].

However, although consumer change and competing providers might be sufficient for ordinary commodities to ensure efficiency, it is not the case in the health care market. Consumers are quite often not in a position to judge the quality of care and, as a result of extensive coverage by insurance, not cost-conscious. 'Professional ethics' restrict competition among providers to limited forms of competition. In such an environment of restricted competition and consumer ignorance about product or service quality, without proper controls and checks on producer behaviour, there is plenty of scope for abuse and excesses and consequently inefficiency. The standard forms of checks and controls such as licensing, ethical standards, self-regulatory measures by the medical profession, seem insufficient to countervail the powerful economic incentive generated by a fee for service system.

There is evidence of some gross inefficiencies in parts of the Belgian health care system. Some inefficiencies are the result of an absence of quality checks, standards and monitoring of provider behaviour, in those seciors where consumer ignorance is highest. Other inefficiencies are due to the practice of setting national fees (the 'nomenclature'). Overpricing of medical services - e.g. prices far in excess of costs including normal profits, or prices lagging behind huge productivity gains through learning leading to excessive rents-stimulate their practice or prescription far beyonu diagnostic or therapeutic relevance.

Laboratory testing (and radiology) provides a clear example of these excesses. Inpatient laboratory testing was financed fee for service up to 1988. Productivity gains in laboratory testing, reflected in lower fees only with a lag and leaving substantial rents per service, and the absence of quality standards and monitoring, lead to excessive prescription by GPs, specialists and hospitals. Hospitals, having feesplitting arrangements with their specialists, used their laboratories as means to generate additional revenue, stimulating the volume of laboratory testing. In 1985 HIAs, medical doctors and the government decided on a national budget. If the budget were exceeded, fees were to be cut proportionally. As there were no volume checks on provider behaviour, the fee cut was met by an almost proportional increase in volume. This provides a clear example of inefficiency i.e. a volume of services that is largely unrelated to diagnostic value but in sheer response to financial considerations. From 1988 onwards, a new financing mechanism was gradually implemented, based on a payment per day and an additional payment per admission for in-patients. Large and specialized laboratories are active in this field. Fee-splitting and kickbacks-although illegal-to prescribing GPs and specialists are not uncommon. A 'diluted' fee for service system is maintained for out-patients because a degressive fee schedule and peer review discourages overprescribing. These new methods of direct government control by fixed budgets and sanctions if budgets are exceeded have brought expenditures as well as the level of volume under control. It limits gross inefficiencies by overprescribing. It does, however, little to remedy inefficiencies at the micro-level. The crude methods of fixing budgets at the micro levelusually freezing budgets at historic levels-rewards previously inefficient behaviour.

Large regional variations in medical consumption, not accounted for by differences in patient composition but attributed to differences in 'style of practice', are another indication for the existence of inefficiencies. A complicating factor is that-to a large extent-these differences arc largest between the north and the south of the country. In the Belgian political context, with recurrent tensions between Flanders, Brussels and Wallonia, regional statistics have a special meaning. Although several constitutional reforms since 1980 have shifted important functions (economic policy, education, culture, environment, public health, ...) to the three regions (Flanders, Brussels, Wallonia) or communities (Flemish, French), social security is still a federal program with uniform rules and regulations across the country. Those politically thriving on emphasizing the heterogeneity of the country and nationalistic feelings, are constantly on the look-out for differences in costs and benefits, generated under national rules, between Dutch-speaking Flanders, French-speaking Wallonia and the bilingual region of the capital Brussels. The general debate is about the financial transfers within the social security system. It was estimated that the transfer of Flanders and Brussels to Wallonia annually amounted to approx. 100 billion BF but is likely to decrease in the future [12]. The transfer is mainly caused by differences in revenues generated, rather than differences in expenditures. Considering only health insurance, the net transfer from Flanders and Brussels to Wallonia in 1989 was estimated at approx. 25 billion BF [13]. Again $85-90 \%$ of this transfer is due to differences in the revenue generating capacity of the regions, rather than differences in medical consumption. For some politicians such transfers are excessive and they argue for the devolution of social security programs to the regions. As social security is one of the last major federal programs, some argue that its devolution would put the existence of Belgium as a country in jeopardy.

On the side of this major and recurrent political discussion, data on regional differences in medical consumption and expenditures per capita were produced, showing large variations between areas and regions. According to one study [14] some $40 \%$ of these variations in medical consumption can be explained by patient characteristics such as age, income, labour market status, education, environmental fac- 
tors and by supply characteristics. The remainder of the variation is attributed to specific regional influences and or differences between HIA enrollment. The precise mechanisms generating the differentials are unknown but regional differences in 'style of medical practice' and differences between HIAs in using the rulebook on cost reimbursements are suggested as possible explanations. But it also suggests inefficiency in medical practice induced by inappropriate incentives.

\section{OPTIONS FOR REFORM}

Two opposite scenarios for reform of the Belgian health care system have recently been proposed. These will be briefly described and compared to a third alternative based on the ideas of managed competition.

\subsection{Direct governmental budgetary control}

Beeckmans [15] defends the new cost containment strategy that was introduced on January 1st 1991, which is essentially a system of tight budget control. The key elements of this reform are as follows.

(1) The government annually decides ex ante on the global budget to be allocated to the health insurance sector as a whole, and to some of its subsectors. In cases of overspending, the Minister is required to take remedial action to either compensate for the amount of overspending (in the case of hospitals and laboratories) or to prevent future overspending (all othu, cases).

(2) Per subsector, providers and HIAs collectively have to negotiate how to allocate the global budget, e.g. by means of fee agreements. If these parties fail to negotiate an agreement, the government (by means of the Management Committee of the RIZIV), in its role of decision maker of last resort, is bound to take action to meet the budgetary targets.

(3) A Special Committee for Budgetary Control reviews the expenditure patterns on a quarterly basis. This signalling function aims at a better and, above all, quicker response to any signs of overspending.

It is clear that under this option the role of the third party payers remains limited to negotiator on behalf of all the insured collectively and to the administrative tasks of reimbursement and control of provisions. It is too early to judge the effectiveness of this new budgetary mechanism of cost containment. A major problem remains the arbitrary allocation of budgets over the various types of health care. It is hard to see how improvements in allocative efficiency, for instance by means of substitution of outpatient for inpatient care through technological advances, will be implemented in such a rigid budgetary system.
Another weakness of this approach seems to be the uncertainty regarding the outcomes of conflicts when providers and insurers are unable to negotiate an agreement over prices.

\subsection{Three-stage financial responsibility of insurers}

By law of 1963, HIAs have a closed budget consisting of their revenues-which is the sum of income-related and supplementary premium payments of their members-with which they have to cover their expenses. The latter is mainly the reimbursement of (part of) the expenditures for care received by the members and operating costs. The legal financing rule of income-related supplementary premiums is rather inequitable. An HIA insuring high income earners would enjoy higher revenues and lower expenditures as high income earners are generally healthier.

Despite the obvious incentives for selection of low-risk and high-income insured, active "cream skimming' has not occurred. This was mainly a consequence of the fact that the legal obligation for HIAs to cover any deficits from additional supplementary premiums has never been enforced. Actual allocations to the HIAs from the Central Fund have in the past usually been made according to reimbursement claims rather than the legally prescribed revenues. Rather than following the lawful (but inequitable) mechanism, actual practice in effect merely implied claims reimbursement and subsidies from 'surplus" HIAs to "deficit' HIAs. Clearly, as the method of cost reimbursement does not stimulate cost-consciousness, it is therefore not surprising that gradually global deficits have become much larger than surpluses. By ad hoc government decisions, these deficits were generally covered by government subsidies.

Kesenne [2] has proposed to put greater emphasis on the financial accountability mentioned in the 1963 law. However, he does not propose to merely enforce the law, adapt the capitation formula and hold the individual HIAs financially responsible for their operations. Instead, he proposes to divide the responsibility between three levels: government, HIAs collectively and HIAs individually. Each level would be held responsible for a certain share (e.g. 25-50-25\%) of any deficits occurring at the global level. Each level would have to take appropriate action to recover deficits. Some instruments of budget control would remain the exclusive domain of the government such as planning of health care facilities, registration of drugs, etc. However, other areas would remain a collective responsibility of the HIAs such as tariff and fee agreements with providers. He also proposes that the means which are currently available to HIAs, such as the monitoring and control of providers with respect to the appropriateness of care delivered, should be complemented with managed care-type or selective contracts with providers.

This rather complex subdivision of responsibility seems to be based on three assumptions, i.e.: 
(1) that it is impossible to construct a 'fair' capitation formula to allocate the total revenues between the individual HIAs on the basis of the characteristics of their insured populations;

(2) that HIAs collectively represent more bargaining power to negotiate fees with providers than each HIA individually; and

(3) that the government should retain some crucial regulatory power and therefore also part of the financial responsibility.

A serious drawback of the proposed system of shared financial responsibility appears to be the dramatic dilution of the powerful incentive arising from full and clear financial responsibility. Worse even, this system appears to run the risk of creating numerous free rider problems: every 'level' and indeed even every HIA will benefit from the efforts on cost control of the other 'responsables'. This feature may unintentionally reduce the incentive to try to balance revenues and outlays. Despite the substantial limitation of each HIA's individual responsibility, the proposed system still requires the construction of a 'fair' capitation formula to divide the last $25 \%$ of any deficit (or surplus!) over the various HIAs.

\subsection{Regulated competition}

To avoid the shortcomings of the two strategic options discussed above, we suggest a possible third alternative way forward for the Belgian health care financing, thereby reiterating some of our previously formulated $\mathrm{i}^{-1}$ eas [16]. At first glance, it appears that reshaping the Belgian health care market to more closely resemble managed competition would require fewer changes than in countries like the U.K. and the Netherlands where such decisions have recently been taken. A sponsor- of the Enthoven [17] type defined as 'an agency that assures eligible beneficiary financial coverage of health care expenses at a reasonable price'has always been at the core of the postwar Belgian health care system. The Belgian National Health Insurance Instite (RIZIV) is the prime candidate to become the 'active, intelligent, collective agent on the demand side to structure and adjust the market in a continuing, but never completely successful, effort to overcome its tendencies to failure.'

Some crucial prerequisites for a true species of managed competition to come about have, however, always been lacking. We will briefly review the major characteristics of a system of managed competition and to what extent they would require adaptation of the current Belgian system.

Financial accountability of insurers. Health care revenues currently already are collected centrally by means of taxes and social insurance premiums (payroll taxes) which ensure a fair degree of solidarity according to ability to pay. But for any type of regulated competition to be given a chance to work, the perverse financing mechanism of allocating rev- enues to HIAs on the basis of income-related premiums paid by HIA members would have to be radically changed into a, preferably health-adjusted, capitation formula. The HIAs should receive an annual payment from the Central Fund for each individual insured which reflects a percentage (e.g. $85 \%$ ) of the average medical care expenses. The (actuarial) categories representing the various health risks should not only depend on a few simple characteristics such as age and sex but ideally also include good proxies for health status. The remaining percentage of the expenditures (e.g. 15\%) needs to be covered from premiums directly paid by the insured. To avoid premium differentiations, these premiums have to be community rated, i.e. they are flat rate premiums which may differ between insurers but which are equal for all insured of the same insurer.

Ironically, a very similar allocation mechanism has been proposed already in a law of 1949 but apparently has never been applied because of lack of consensus as to what risk factors ought to be included in the capitation formula [18]. One of the variables which is commonly quoted in the Dutch discussions as crucial is place of residence. More than in most other countries this regional aspect has an explosive character in Belgium. It is well known that there are large differences in medical consumption between the northern and the southern region. Several investigators have sought to identify which part of this variation can be explained by observable proxies for need differences and concluded that a large part remained unexplained. It is hypothesized that part of the unexplained variation is due to supply factors (e.g. differing practice styles). Although it seems in principle unfair that a capitation formula should account also for such supply differences by granting higher capitation payments to e.g. residents of high consumption areas, it is politically inconceivable that, at least in a first phase, such differences would not be taken into account in the payments. One possibility to overcome this problem would be to start off with a formula that accounts for regional differences but to gradually phase out the weight of the regional element over a number of years.

As in any other system, the development of an adequate formula would be of great importance and not an easy task at all. However, given the recent findings that - apart from demographic variablespast use of the health care system is one of the best predictors of future expenditures (see e.g. $[19,20]$ ), the Belgian current situation in which data are routinely collected on the use of all types of health care services paid fee-for-service has some advantages. These huge records data bases gathered by the HIAs could be used as a starting point to devise an initial capitation formula.

If, on the basis of such a formula, competing HIAs would receive a closed budget with which to pay for the health care expenditures of their insured, it would no longer be unfair to force them to at least break- 
even. They would become truly Accountable Health Plans in the Enthoven sense [21]. HIAs which are successful in improving the cost-effectiveness of health care delivery while maintaining high quality care should be rewarded by allowing them to reserve any operating surpluses or pass the profits on to their insured by offering lower premiums. Of course, they would then also have to be given more instruments than they currently have to control costs effectively and stimulate cost-effective behaviour by health care providers.

Insurer-provider relationship. Undoubtedly, one of the most powerful means of introducing costeffectiveness considerations into treatment decisions is to alter provider payment schemes. Currently, insurers are legally required to reimburse at centrally agreed fees all care that is provided by registered providers to their insured. If they were to be held financially accountable for their operations, they are also to be given the opportunity to pass on this incentive for efficiency to the providers of care. This could mean as little as small variations in fec schedules or monitoring to as much as radical departures from fee-for-service payments and even selective contracting with preferred providers. Given the current excess supply of physicians and the high density of most other health services in Belgium, the chances for success of selective contracting do not seem to be very low. It would mean the end of complete freedom of choice of doctor for those patients subscribing to such policies with reduced choice. Fierce opposition from the organized medical profession for such ideas can be expected. ( - course, the selectivity can take many forms, going from yes/no reimbursement to lower reimbursement percentages for non-preferred providers. The fact that some HIAs now already operate their own services (outpatient clinics, pharmacies, ...) and have closer links with some hospitals than others could ease any developments towards preferred-provider arrangements.

In addition, preferred-provider arrangements would open up possibilities for experiments with financial reward systems other than the currently prevailing fee-for-service system. Similar to the developments in the US health maintenance organizations (HMOs), one would gradually expect the use of prepaid capitation payments or at least mixed capitation/fee-for-service payment schemes to rise quickly. The HMO idea does, of course, assume that any efficiency gains arising from the integration of the insurer and provider function can be passed on to consumers by means of premium reductions.

Insurer-insured relationship. For managed competition to work, the third party payers also have to be given an incentive, not only to contain costs but also to aim at the best price/quality ratio. In other words, insurers have to be rewarded not for providing just the lowest cost health insurance policies but rather for insuring the best possible cost/quality combi- nation. Insured must have the option to select the insurer of their choice. At present, this choice is limited in Belgium to one of the six HIAs. In order to make competition workable, it seems desirable to make this market contestable in the medium run to reduce the risk of collusive arrangements. It seems hard to defend why newcomers in the health insurance market, e.g. private companies, should be denied cntry provided they abide by the same set of rules of competition.

As in most proposals for managed competition, such pro-competitive regulation would have to include open enrolment, community rating, a basic package option and certain requirements regarding the provision of information about alternative health plans to avoid cream skimming by risk selection [22]. Compliance with all of these rules would make both the existing HIAs and the newcomers eligible for capitation payments from the Central Fund for their insured. As in any other proposal for managed competition, the question remains to what extent a fine-tuned capitation formula and pro-competitive legislation will suffice to prevent cream skimming [23].

The importance of this need for contestability of the market in the Belgian context should not be underestimated: the current ideological and political alignment of the existing HIAs carries a great risk that competition for insured may take place through non-health related benefits (e.g. other social welfare services) rather than through just health insurance premiums. Despite the possibility of switching HIAs every three months, the mobility of insured has traditionally been fairly low.

Many crucial features of such a competitive design call for further thought and discussion before implementation can be even considered. One important matter to be resolved is what types of health services will have to be included in the basic benefits package and which services will be left to complementary insurance. Up until now, the Belgian health insurance coverage has been fairly comprehensive. A legitimate question is whether all of the current entitlements of the National Health Insurance program would have to be included in a basic insurance package. A related question is what share of this basic entitlements package would have to be covered by the capitation payment and what share would have to be accounted for by the (flat, community-rated) premium to be charged by the HIAs to their insured. Is there a role for cost-sharing by deductibles and copayments and to what extent would it be allowed to re-insure these out-of-pocket payments? Can a managed health insurance market coexist with national planning of health care facilities?

Answers to these and other questions will have to come from political debate informed by research findings. As interest in regulated competition in health care is growing in countries other than the United States, also the research evidence on the 
feasibility or workability of such designs is accumulating [24-26].

\section{CONCLUSION}

Eight years ago, at an international conference held in Antwerp in 1985 on Economic Incentives in Health Care with a substantially overlapping speaker's programme as today's conference, we already attempted to draw some conclusions for Belgium [16]. We concluded then that:

Putting the general principle of reinforcing the agency role into practice in the Belgian health care setting would require a redefinition of the role of the sickness funds. (...) There seem to be two major ways in which the sickness fund's role could be strengthened by putting them financially at risk. The regulatory approach would imply that they get fixed budgets from the national social security budget for which they would have to cover their beneficiaries for a prespecified set of risks. (...)

The regulated-competition approach would require more profound changes in the system. [16, p. 113].

Today it seems that much of the financing and cost containment problems are still the same but that, unlike in 1985, there is more debate about the incentive role to be played by designating financial accountability. Although recent government policies are no evidence of a belief in the importance of strengthening the role of third-party payers, we still think that enhancing their role in a pro-competitive environment will be crucial in any attempt to reshape the system to make it efficient and affordable while keeping it equitable.

Acknowledgements-We thank Jan Beeckmans, David Chinitz, Diane De Graeve and Jos Kesenne for their valuable comments. Of course, the authors remain fully responsible for any errors and for the views expressed in the paper. Eddy van Doorslaer would like to acknowledge the Dr Paul Janssen Institute for financial support through the Special Chair in Health Economics at the University of Antwerp.

\section{REFERENCES}

1. Schieber G. J., Poullier J. P. and Greenwald L. M. Health care systems in 24 countries. Hlth Affairs 10, 22, 1991 .

2. Kesenne J. Financial responsibility of the mutualities in Belgium. In Health Care: a Matter for Government or for Insurers and Providers? (Edited by Naaborg $\mathbf{R}$. and Kesenne J.), pp. 31-47. Datawyse, University Press, Maastricht, 1992 (in Dutch)

3. Hurst J. W. The Reform of Health Care. A Comparison of Seven OECD Countries. OECD, Health Policy Studies No. 2, Paris, 1992.

4. Belgisch Instituut voor Gezondheidseconomie. Com pendium Gezondheidsstatistiek 1992. Belgisch Instituut voor Gezondheidseconomie, Brussel, 1992.

5. Zweifel P. and Eichenberger R. The political economy of corporatism in medicine: self regulation or cartel management? J. Regul. Econ. 4, 89, 1992.

6. Private sector employers are legally required to cover their employees against occupational hazards and against risks during travel from and to their place of work. To comply with the law, employers can choose from a range of private for-profit companies, most of them operating as HMOs (medical care at a prepaid fes). This market is a highly competitive private market with limited government interference.

7. Nonneman W. and van Doorslaer E. A model of the labour market for physicians. In Competition in the Dutch Health Care (Edited by Hagen J. H.). De Tijdstroom, Lochem, 1985 (In Dutch).

8. The 'asymmetry of ethical norms' is noteworthy. Price cutting is 'unethical', whereas there seem to be no objections to premiums above the negotiated fees. It is generally known and a widespread practice in specialist services in excess demand, that these premiums are settled in cash, dodging income tax.

9. OECD. Health Data. OECD, Paris, 1993.

10. Wouters R., Spinnewijn H. and Pacolet J. The Profit of the Non-profit. Report to the Koning Boudewijn Stichting, Hoger Instituut voor de Arbeid, Leuven, 1988 (In Dutch)

11. Spinnewijn H. and Pacolet J. Financial Flows and Employment in Health Care in Flanders. Hoger Instituut voor Arbeid, Katholieke Universiteit, Leuven, 1993 (In Dutch).

12. Detheé $\mathbf{M}$. Regional analysis of the social security 1985-1989. In Social Security and Federalism (Edited by Deleeck H.). Die Keure, Leuven, 1991 (In Dutch).

13. Alliance of Christian Mutualities. Regional Analysis of the Health Care Sector. LCM-info dossier No. 18. Alliance of Christian Mutualities, Brussels, 1992 (In Dutch).

14. Schockaert E., Van Dongen $H$. and Dhaene $G$. Investigation into the Differences in Medical Consumption in Belgium. Report to the INAMI/RIZIV, Catholic University of Louvain, Louvain, 1991 (In Dutch).

15. Beeckmans J. Financial responsibility of insurers. In Health Care: a Matter for Government or for Insurers and Providers? (Edited by R. Naaborg and J. Kesenne), pp. 49-67. Datawyse, University Press Maastricht, 1992 (in Dutch).

16. Nonneman W. and van Doorslaer E. Economic incentives in the health care industry: implications for health policy making. Hlth Policy 7, 109, 1987.

17. Enthoven A. C. Theory and Practice of Managed Competition in Health Care Finance. North-Holland, Amsterdam, 1988. See also Enthoven A. C. Managed competition of alternative delivery systems. J. Hlth Politics, Policy Law 13, 305, 1988.

18. De Brabanter $M$. Financial accountability in the Belgian compulsory health insurance. De Gids op Maatschappelijk Gebied 83, 821, 1992 (in Dutch).

19. Newhouse J. P., Manning W. G., Keeler E. B. and Sloss E. B. Adjusting capitation rates using objective health measures and prior utilization. Hith Care Financing Rev. 10 (4), 41, 1989.

20. Van Vliet $R$. and van de Ven W. Capitation payments based on prior hospitalization. Hlth Econ. 2, 177, 1993.

21. Enthoven A. C. On the ideal market structure for third-party purchasing of health care. Soc. Sci. Med. $39,1413,1994$.

22. See e.g. van de Ven W. From regulated cartel to regulated competition in the Dutch health care system. Eur. Econ. Rev. 34, 632, 1990.

23. Van de Ven $W$, and van Vliet $R$. How can we prevent cream skimming in a competitive health insurance market? The great challenge for the 90's. In Health Economics Worldwide (Edited by Frech T. and Zweifel P.), pp. 23-46. Kluwer, Amsterdam, 1992. See also Van Vliet $R$. and van de Ven $W$. Towards a capitation formula for competing health insurers. Soc. Sci. Med. 34, 1035, 1992. 
24. Schut F. T. Workable competition in health care prospects for the Dutch design. Soc. Sci. Med. 35, 1445, 1992.

25. Chinitz D. P. Reforming the Israeli health care market. Soc. Sci. Med. 39, 1447, 1994.

26. van de Ven W. and Schut F. T. Should cata- strophic risks be included in a regulated competitive health insurance market? Soc. Sci. Med. 39, 1459, 1994.

27. National Institute for Statistics. Belgian Statistical Yearbook, 1990. National Institute for Statistics, Brussels, 1990. 